Article

\title{
Electrospun Silver Coated Polyacrylonitrile Membranes for Water Filtration Applications
}

\author{
Shalv Amit Parekh ${ }^{1,+}$, Rebecca Nicole David ${ }^{1,+}{ }^{+}$Kranthi K. R. Bannuru ${ }^{1,+}$, \\ Lakshminarasimhan Krishnaswamy ${ }^{1}$ and Avinash Baji 1,2,* (iD \\ 1 Engineering Product Development, Singapore University of Technology \& Design, Singapore 487372, \\ Singapore; shalv_parekh@mymail.sutd.edu.sg (S.A.P.); rebecca_nicole@mymail.sutd.edu.sg (R.N.D.); \\ kranthi_bannuru@mymail.sutd.edu.sg (K.K.R.B.); 1_krishnaswamy@sutd.edu.sg (L.K.) \\ 2 Department of Engineering, School of Engineering and Mathematical Sciences, La Trobe University, \\ Bundoora, VIC 3086, Australia \\ * Correspondence: a.baji@latrobe.edu.au \\ + These authors contributed equally to this work.
}

Received: 6 July 2018; Accepted: 3 August 2018; Published: 8 August 2018

\begin{abstract}
The scarcity of drinking water and the contamination of water sources in underdeveloped countries are serious problems that require immediate low-tech and low-cost solutions. In this study, we fabricated polyacrylonitrile (PAN) porous membranes coated with silver nanoparticles (AgNP) and demonstrated their use for water filtration and water treatment applications. The membranes were prepared by electrospinning a PAN solution and treating in a hydroxylamine $\left(\mathrm{NH}_{2} \mathrm{OH}\right)$ aqueous solution to form $-\mathrm{C}\left(\mathrm{NH}_{2}\right) \mathrm{N}-\mathrm{OH}$ groups that were used for functionalization $\left(\mathrm{Ag}^{+}\right.$ions) of the membrane. The coordinated silver ions were then converted to silver nanoparticles. The microstructure of the membrane, water permeability, antimicrobial effect (using Escherichia coli), and particulate filtration capabilities were studied. This study verified that the membrane demonstrated a $100 \%$ reduction for Gram-negative bacteria with an effective filtration rate of $8.0 \mathrm{~mL} / \mathrm{cm}^{2} \mathrm{~min}$. Furthermore, the membrane was able to eliminate $60 \%$ of latex beads as small as $50 \mathrm{~nm}$ and over $80 \%$ of the $2 \mu \mathrm{m}$ beads via gravity filtration. This study demonstrated that PAN-AgNP membranes can be employed as antimicrobial membranes for the filtration of water in underdeveloped countries.
\end{abstract}

Keywords: polyacrylonitrile; electrospinning; antibacterial; silver nanoparticles; water filtration

\section{Introduction}

Water shortage and the availability of clean drinking water sources are of serious concern in most developing and developed countries. To address these issues, researchers have utilized porous membranes for developing filter media that can be used for water purification and water treatment. Various polymers have been used to fabricate electrospun membranes, such as polyacrylonitrile (PAN), polysulfone (PSU), polyethersulfone (PES), polyvinylidene fluoride (PVDF), polypropylene (PP), and cellulose acetate [1-15]. PAN has excellent properties, including high mechanical properties, a unique thermal stability, and an ability to undergo pre-spinning and post-spinning modifications [2-6,9,12-14,16-28]. Furthermore, PAN porous membranes produced using various processing techniques have been widely investigated for water filtration applications [1-24,26,29,30]. Compared to other conventional processing techniques, electrospinning has obtained tremendous interest among researchers as the process is simple, reproducible, cost-effective, and scalable for the development of porous membranes for water filtration and treatment [2-5,7,8,10,11,15,18-20,26-29]. Additionally, PAN membranes fabricated using electrospinning can be functionalized using various 
chemicals to make them anti-bacterial and anti-microbial [1,4,5,7-12,14,16,18,21,22,26,27]. membranes can potentially be used for water filtration in underdeveloped countries to combat the growing need for an affordable and effective filtration method to provide clean and safe drinking water.

Recently, silver nanoparticles have been incorporated in membranes for water filtration due to their anti-microbial property $[4,5,7,11,14-16,21-24,27]$. In this study, we use electrospinning to fabricate silver nanoparticles (AgNP) coated PAN membranes and demonstrate their use for water filtration and treatment. Previous studies have shown that antimicrobial agents such as silver can be incorporated into the fibrous membrane by simply dispersing them into the electrospinning solution prior to electrospinning. However, it has been reported that the incorporation of antimicrobial agents within the fibre matrix may not impart antibacterial properties evenly in the membrane $[6,13,22,23,30]$. In this study, we first used electrospinning to fabricate PAN fibrous membrane and then coated the surface of the fibres with silver particles. This step enabled a higher retention of silver nanoparticles on the membrane compared to dispersing silver particles within the electrospinning polymer solution $[6,13,16,20,22]$. The membranes were investigated for antimicrobial efficacy against Escherichia coli bacteria $[2-4,6,8-12,14-16,24,26,27,30,31]$, water permeability, and particulate filtration capabilities using amine-modified blue fluorescent latex beads $[4,19]$. The results indicated that the membranes possessed antimicrobial functionality to kill bacteria and stop their colony growth. Water permeability test is used to investigate the water filtration rate of the membranes. Furthermore, the particulate filtration test showed that the membranes can separate an acceptable number of particles with sizes as small as $50 \mathrm{~nm}$ diameter. This demonstrates their ability to filter contaminant particles from the water.

\section{Materials and Methods}

\subsection{Materials}

The polyacrylonitrile (PAN) (Mw: 150,000) used in this study was obtained from Scientific Polymer Products, Inc. (Ontario, NY, USA). N,N-dimethylformamide (DMF) was purchased from TEDIA (Fairfield, $\mathrm{OH}, \mathrm{USA})$. Other materials, such as acetone, hydroxylamine $\left(\mathrm{NH}_{2} \mathrm{OH}\right)$, and silver nitrate $\left(\mathrm{AgNO}_{3}\right)$ were purchased from Sigma Aldrich (Singapore).

\subsection{Solution Preparation}

The electrospinning solution was prepared by dissolving $16 \mathrm{wt} . \%$ PAN in DMF. The solution was heated at $70{ }^{\circ} \mathrm{C}$ for $8 \mathrm{~h}$ to ensure the complete dissolution of PAN.

\subsection{Electrospinning}

The freshly prepared solution was filled in a $10 \mathrm{~mL}$ syringe with a 21-gauge Terumo stainless-steel flat round tip needle. A schematic of the electrospinning set up is shown in Figure 1. A rotating drum with aluminium foil was used as a collector, at a distance of $15 \mathrm{~cm}$ from the spinneret. A voltage of $15 \mathrm{kV}$ was applied to the needle using a built-in voltage source, and the flow rate for the solution was $0.5 \mathrm{~mL} / \mathrm{h}$, maintained using a syringe pump. The controlled environmental conditions were set at a temperature of $25^{\circ} \mathrm{C}$ and relative humidity of $75 \%$. A $10 \times 10 \mathrm{~cm}^{2}$ PAN membrane was fabricated using $30 \mathrm{~mL}$ of the solution. The aluminium foil containing the membrane was removed and dried in an oven overnight at $60^{\circ} \mathrm{C}$.

\subsection{Surface Functionalization}

The following steps were used to coat the surface of fibres with silver particles. In the first step, the electrospun PAN membrane was completely immersed in $1 \mathrm{M} \mathrm{NH}_{2} \mathrm{OH}$ for $20 \mathrm{~min}$. This was followed by an immersion in $0.1 \mathrm{M} \mathrm{AgNO}_{3}$ aqueous solution at $25^{\circ} \mathrm{C}$ for $1 \mathrm{~h}$ to allow the amidoxime groups from $\mathrm{NH}_{2} \mathrm{OH}$ to coordinate with the silver ions $\left(\mathrm{Ag}^{+}\right)$. The prepared membrane was then immersed in $0.01 \mathrm{M} \mathrm{KBr}$ aqueous solution for $2 \mathrm{~h}$, followed by a quick immersion in methanol. Finally, 
the membrane was exposed to ultraviolet (UV) for 10 min on each side in the Triad 2000 chamber (DENTSPLY International Inc., York, PA, USA). The membrane was then thoroughly washed in distilled water and left to dry in the oven at $70{ }^{\circ} \mathrm{C}$ for $7 \mathrm{~h}$ followed by vacuum drying.

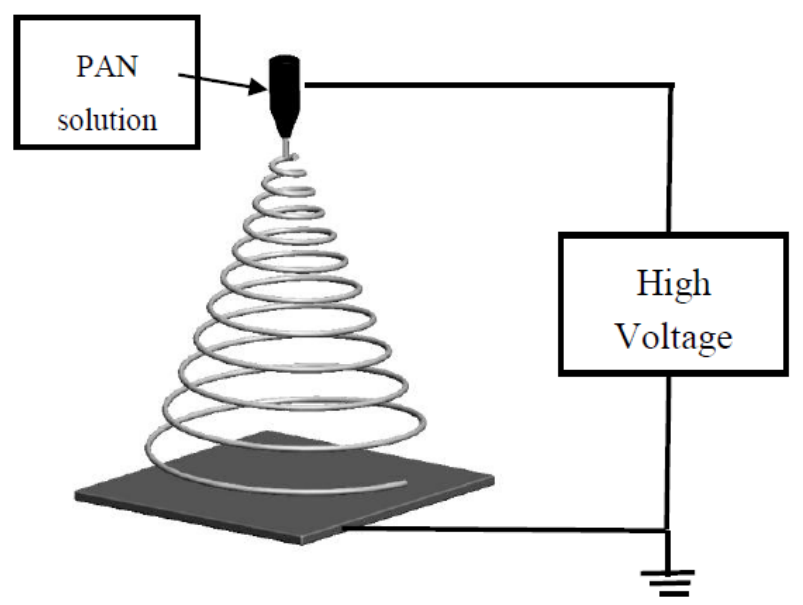

Figure 1. Schematic of electrospinning setup used to prepare the membranes. PAN: polyacrylonitrile.

\subsection{Characterisation}

A scanning electron microscope (SEM, JSM-6700F, JEOL, Tokyo, Japan) was used to investigate the morphology of the PAN and PAN-AgNP membranes. Fourier-transform infrared spectroscopy (Vertex 70, Bruker, Karlsruhe, Germany) was utilised to study the different chemical bonds present in the AgNP-coated and uncoated PAN membranes. The study was done in the Attenuated Total Reflection (ATR) mode. The lattice structures of the samples were studied by $X$-ray powder diffraction (XRD, Bruker D8 Advance diffractometer, Bruker Taiwan) with $\mathrm{Cu} K \alpha(\lambda=0.154 \mathrm{~nm})$ radiation at an accelerating voltage of $40 \mathrm{kV}$.

\subsection{Antimicrobial Tests}

The antimicrobial effect of the PAN membranes with and without silver nano-particles was tested on E. coli cells derived from Top10 cells (Thermo Fischer Scientific, cat C404010 Singapore) as a representative of Gram-negative bacteria. E. coli was cultured in Luria-Bertani broth (LB, Carolina Biological Supply Company, cat.216650, Burlington, NC, USA) in an orbital shaker incubator (YIHDER Technology, LM 510-RD, Xinbei City, Taiwan) at $37^{\circ} \mathrm{C}, 120 \mathrm{rpm}$ for $24 \mathrm{~h}$. The bacteria were harvested by centrifuge, washed with 1 X PBS (phosphate-buffered saline) and then re-suspended in $1 X$ PBS. PBS was prepared by mixing 1 part of 10 X PBS (from Bio-Rad Laboratories, Inc, cat.1610780, Hercules, CA, USA) with 9 parts of sterile ultrapure water. The density of E. coli was determined by spectrophotometry and adjusted to a density of $10^{7} \mathrm{cfu} / \mathrm{mL}$ (colony forming units/millilitre) using $1 X$ PBS. Then, $50 \mu \mathrm{L}$ of this suspension of bacterial cells was placed on samples of the PAN membranes and PAN membranes with silver nano-particles (each $1 \mathrm{~cm}^{2}$ ), for 30 or $60 \mathrm{~min}$. After the defined duration of bacterial contact with the membrane, the membrane was placed in $10 \mathrm{~mL}$ of 1 X PBS solution and vortexed for $2 \mathrm{~min}$. This was done to transfer any remaining bacteria from the membrane to the $1 \times$ PBS solution. Then, $50 \mu \mathrm{L}$ of the $10^{7} \mathrm{cfu} / \mathrm{mL}$ bacteria solutions was directly placed in a separate $10 \mathrm{~mL}$ of PBS solution as a control. The $10 \mathrm{~mL}$ solutions were then diluted serially, and $100 \mu \mathrm{L}$ of the diluent was plated onto LB agar plates (Carolina Biological Supply Company, cat. 216620, Burlington, NC, USA). The plates were incubated at $37^{\circ} \mathrm{C}$ for $20 \mathrm{~h}$, and the number of colonies in each plate was determined. The test was carried out in three replicates for repeatability. 


\subsection{Water Permeability Test}

The permeability of water through AgNP-coated and uncoated PAN membranes was determined using a syringe at a constant flow rate. A $1 \times 1 \mathrm{~cm}^{2}$ membrane sample was cut and exposed under UV light for $5 \mathrm{~min}$. The membrane was placed on the tip of a Terumo $5 \mathrm{~mL}$ syringe such that it allowed for an effective filtration area of $0.186 \mathrm{~cm}^{2}$. The test maintained a constant pressure throughout the experiment under gravity. A total of three membrane samples were tested thrice each, and the corresponding flow rate readings were recorded for each membrane.

\subsection{Filtration Test}

The PAN membranes were cut into $2 \mathrm{~cm} \times 2 \mathrm{~cm}^{2}$ to fit onto the Terumo $5 \mathrm{~mL}$ syringe. A solution of $5 \mathrm{~mL}$ of $800 \mathrm{ppm}$ aqueous solution of two different amine-modified blue fluorescent latex beads of mean particle size of $2.0 \mu \mathrm{m}$ and $50 \mathrm{~nm}$ was pumped in the syringe. The solution was passed through the fabricated PAN membrane at a constant pressure of $50.3 \mathrm{kPa}$. The collected water sample was analysed using spectrophotometry. The results presented here are based on an average of three independent trials.

\section{Results and Discussion}

\subsection{Morphology}

Figure 2 shows the SEM images of the PAN membranes before and after they are coated with silver particles. It is evident from the SEM images (Figure 2) that the PAN membranes are thick with many layers of fibres. The mean diameter of the fibers within the membrane is determined from these SEM images to be $2.36 \pm 0.22 \mu \mathrm{m}$ (Figure 3).

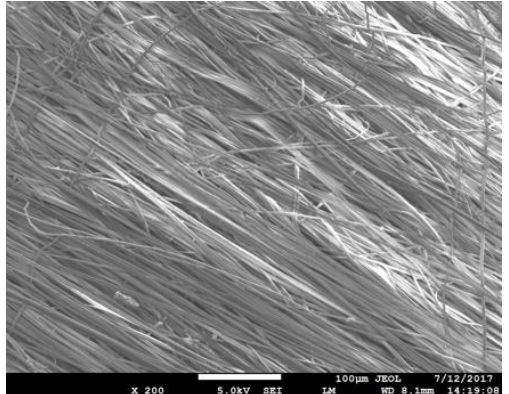

(a)

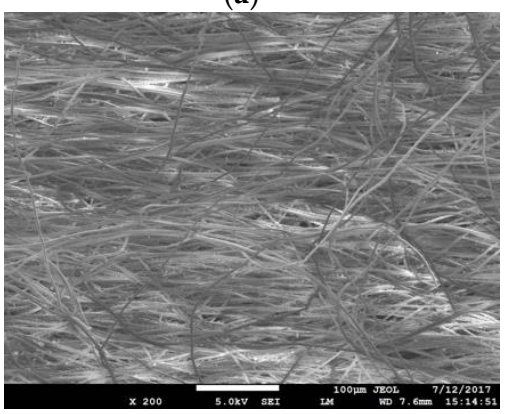

(d)

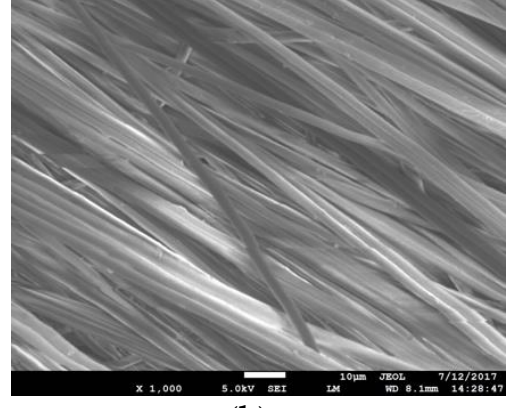

(b)

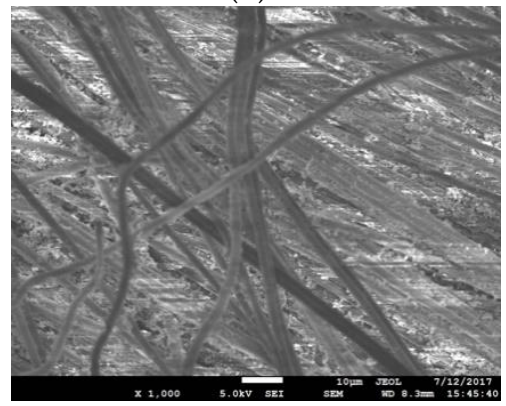

(e)

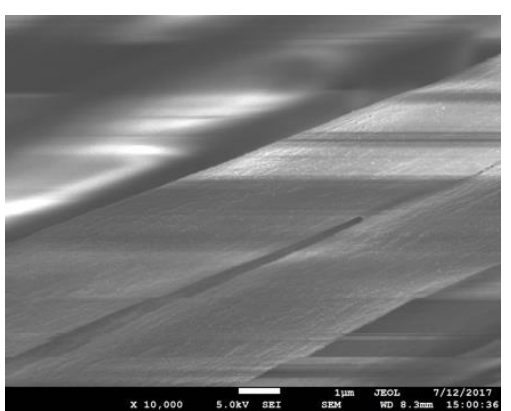

(c)

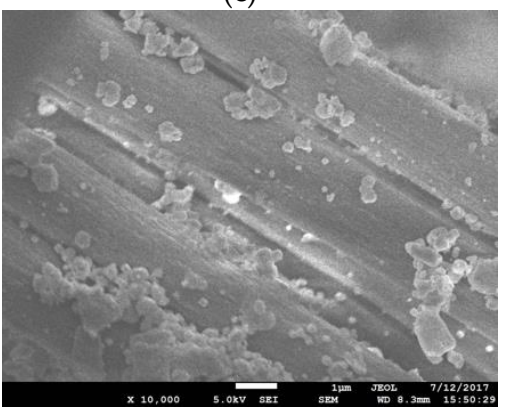

(f)

Figure 2. Scanning electron micrographs (SEM) of electrospun PAN fibres: (a) PAN at $\times 200$ magnification (Scale Bar $=100 \mu \mathrm{m})$; (b) PAN at $\times 1000$ magnification (Scale Bar $=10 \mu \mathrm{m})$; (c) PAN at $\times 10,000$ magnification (Scale Bar $=1 \mu \mathrm{m}$ ); (d) PAN-AgNP (silver nanoparticles) at $\times 200$ magnification (Scale Bar $=100 \mu \mathrm{m})$; (e) PAN-AgNP at $\times 1000$ magnification (Scale Bar $=10 \mu \mathrm{m}) ;(\mathbf{f})$ PAN-AgNP at $\times 10,000$ magnification (Scale Bar $=1 \mu \mathrm{m})$. 


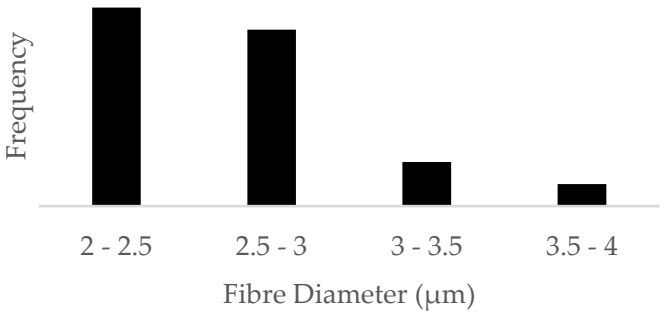

(a)

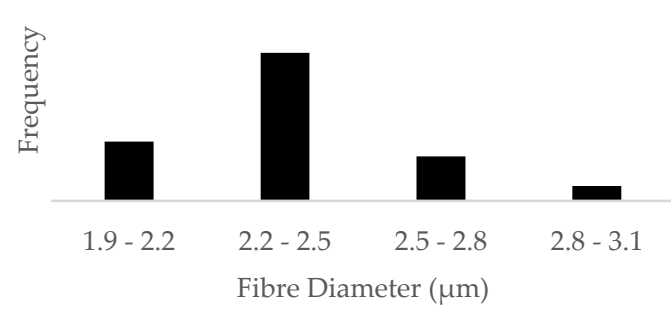

(b)

Figure 3. Histogram size distribution of: (a) PAN; (b) PAN-AgNP.

The incorporation of silver particles on the surface of the fibres is seen to make them hydrophilic. A goniometer is used to estimate the contact angle made by a water drop on these samples using the sessile drop technique. The initial contact angle of the PAN membrane is measured to be $19^{\circ} \pm 4^{\circ}$. On the other hand, the contact angle on silver coated PAN fibers is determined to be $\sim 0^{\circ}$. This indicates that the silver coated membranes are superhydrophilic.

\subsection{Structure}

Fourier-transform infrared spectroscopy (FTIR) is used to investigate the effect of adding silver on the surface of the PAN membrane. Most of the peaks in both samples are observed to be relatively similar, with some discrepancies. This showed that there is no noticeable change in the bonding in PAN and PAN-AgNP. Figure 4 shows the characteristic peak of PAN at $2242 \mathrm{~cm}^{-1}$ (assigned to $C \equiv N)$, which showed no change in the $C \equiv N$ bond with the addition of silver $[2,3,19,23,25]$. Thus, no coordination bond was formed between silver and PAN [3]. The peaks at $1451 \mathrm{~cm}^{-1}$ and $2920 \mathrm{~cm}^{-1}$ displayed the bending and stretching vibrations of the $\mathrm{C}-\mathrm{H}_{2}$ functional group in PAN, respectively $[2,19,23,25]$. The peak at $1630 \mathrm{~cm}^{-1}$ assigned to $\mathrm{C}=\mathrm{O}$ is due to the oxidation of $\mathrm{PAN}$ in air $[2,23,25]$. The peaks at $536 \mathrm{~cm}^{-1}$ and $1630 \mathrm{~cm}^{-1}$ are assigned to $\mathrm{C}=\mathrm{O}$ twisting and $\mathrm{C}=\mathrm{O}$ stretching [23]. The peaks at $1357 \mathrm{~cm}^{-1}$ and $1250 \mathrm{~cm}^{-1}$ are assigned to $\mathrm{CH}$ group vibrations of $\mathrm{CH}_{2}$ and $\mathrm{CH}$, respectively [25]. With an increase in $\mathrm{Ag}$, the peak intensity of $\mathrm{C}=\mathrm{O}$ stretching should increase as well. This is due to the interaction between PAN and Ag with DMF [25].

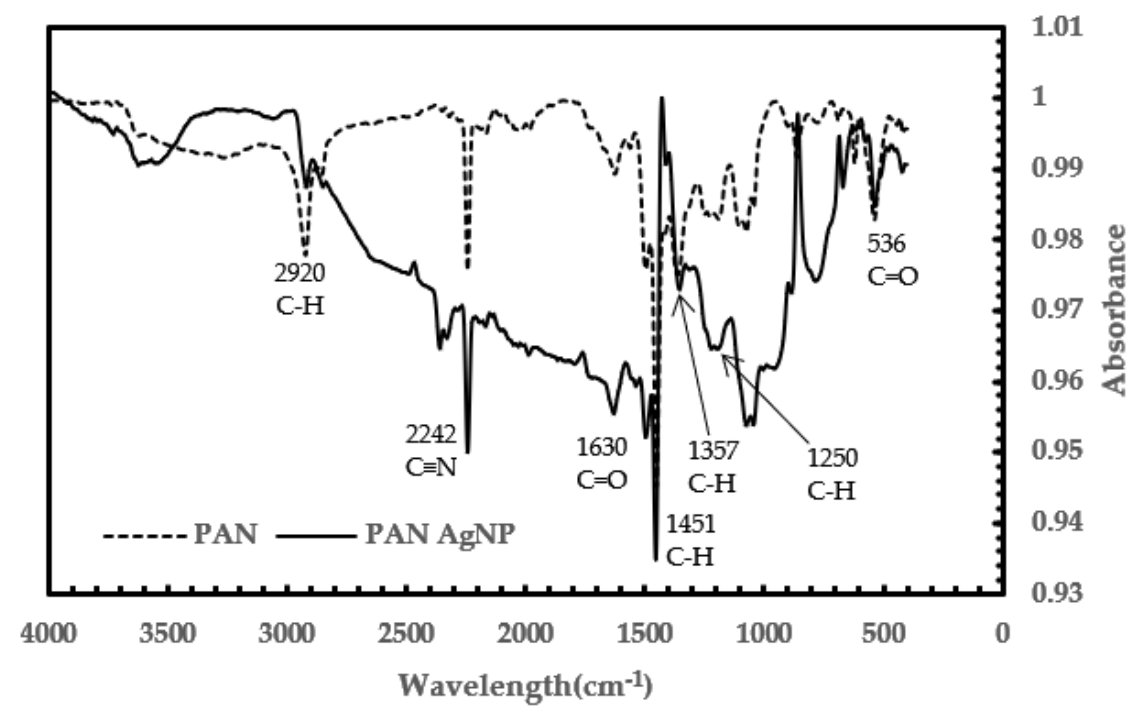

Figure 4. Comparison of Fourier transform infrared (FTIR) spectra of PAN and PAN with AgNP membranes. 
The XRD plots in Figure 5 are used for phase identification to determine the average bulk composition. The PAN microfibres coated with AGNP showed four distinct peaks, at $2 \theta$ values of $38.1^{\circ}, 44.4^{\circ}, 64.4^{\circ}$, and $76.5^{\circ}$. This showed the face-centred cubic (FCC) structure of silver in the silver coated PAN fibers with crystalline planes of silver (111), (200), (220), and (311), respectively [2,3,6,23]. The values we obtained are similar to the values found in the International Centre for Diffraction Data (ICDD) card (card no. 4-783). The XRD results are in agreement with the SEM and FTIR results.

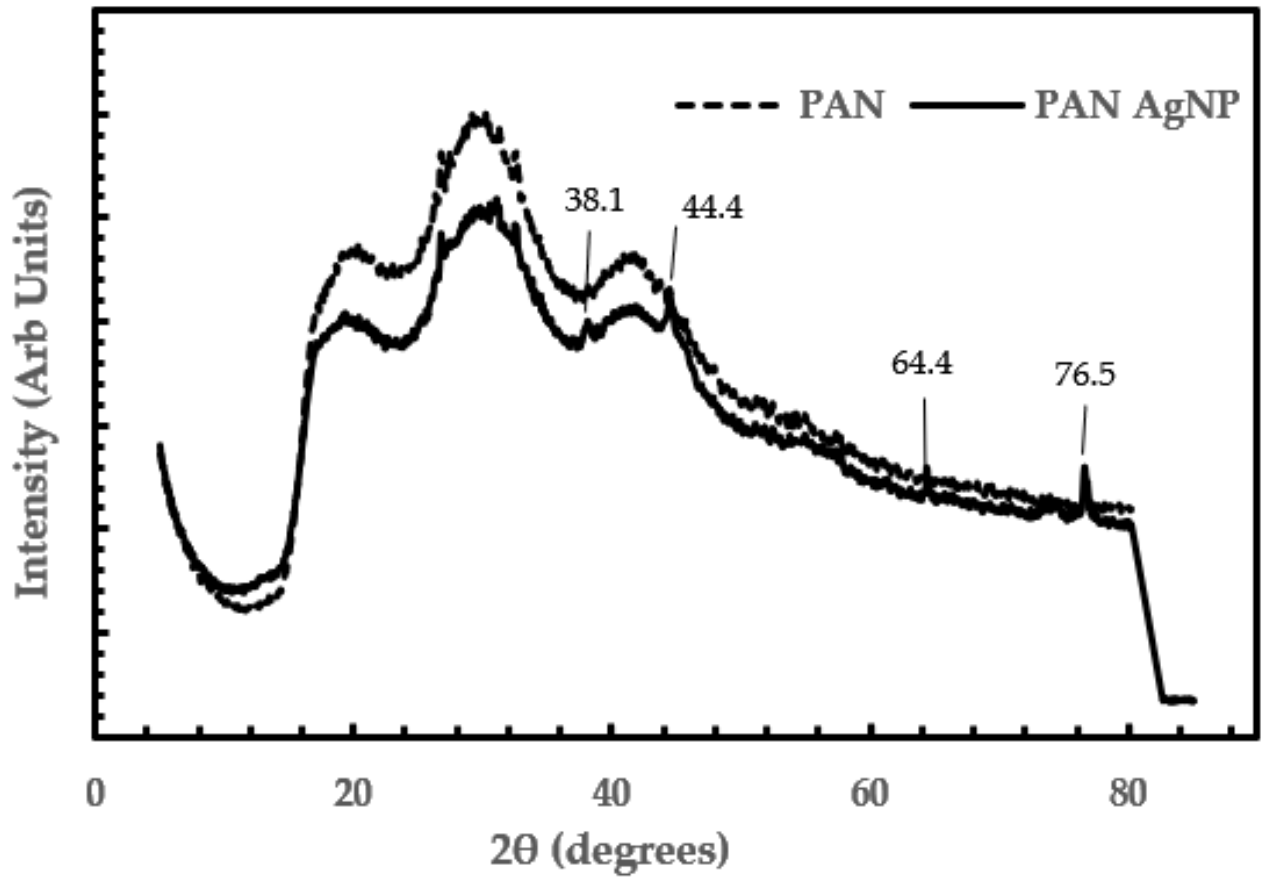

Figure 5. XRD plots of PAN and PAN-AgNP.

\subsection{Antibacterial Test Results}

Table 1 shows the antimicrobial performance of the silver coated PAN membranes. It is clear from Table 1 that there is a significant reduction in the number of bacterial colonies in the solution that is passed through PAN-AgNP membrane compared to the initial control solution. Similarly, the number of bacterial colonies in the solution that is passed through the silver coated PAN membrane is lower than in the solution that is passed through PAN membrane alone. Figure 6 show the digital images of the bacterial colonies on the Agar plates. It is clear that the presence of the AgNP on the membrane inhibited the growth of bacteria. The sample of the filter mesh killed over $99.99 \%$ of bacteria within just 30 min of contact (Figure 6c). Most of the samples had only one colony (Figure 6d), giving an average standard deviation between samples of $0.0045 \%$.

Table 1. Antimicrobial efficacy of AgNP on PAN membranes tested on Escherichia coli.

\begin{tabular}{ccc}
\hline \multirow{2}{*}{ Sample } & \multicolumn{2}{c}{ Percentage Reduction } \\
\cline { 2 - 3 } & $\mathbf{3 0 ~} \mathbf{~ m i n}$ & $\mathbf{6 0 ~} \mathbf{~ m i n}$ \\
\hline PAN (control) & No Reduction & No Reduction \\
E. coli (control) & No Reduction & No Reduction \\
PAN-AgNP Sample 1 & 99.997678 & 99.9995 \\
PAN-AgNP Sample 2 & 99.989017 & 100.000 \\
PAN-AgNP Sample 3 & 99.999213 & 100.000 \\
\hline
\end{tabular}




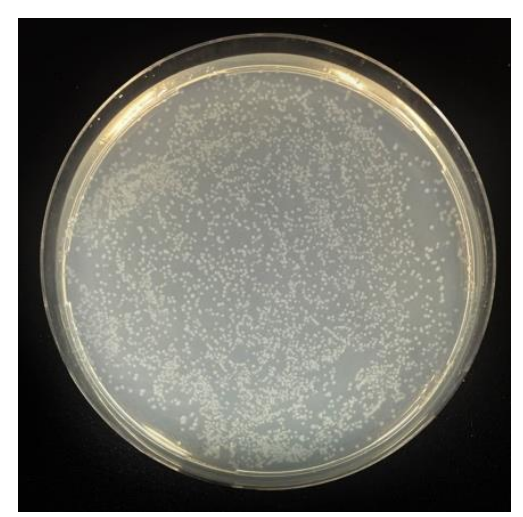

(a)

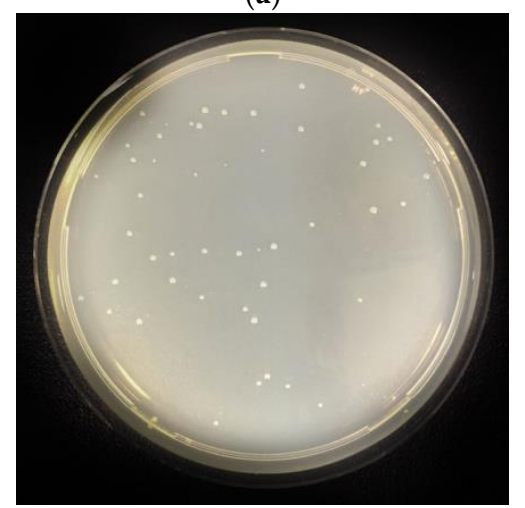

(c)

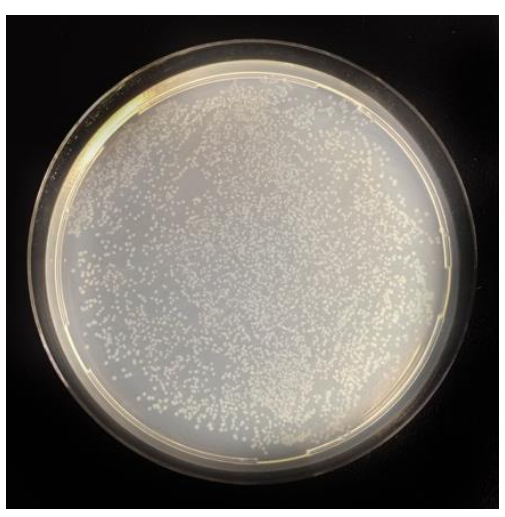

(b)

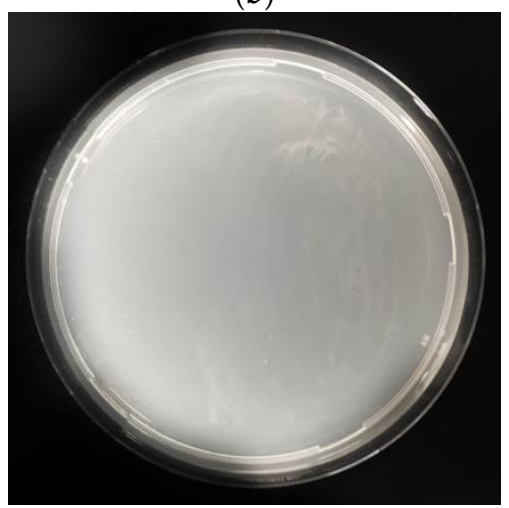

(d)

Figure 6. Agar plates of sample from the (a) Bacterial control; (b) PAN sample control; (c) PAN-AgNP sample (after $30 \mathrm{~min}$ ); (d) PAN-AgNP sample (after $60 \mathrm{~min}$ ).

\subsection{Water Permeability Test Results}

In order to confirm the potential application of the membrane in the filtration process, the permeability behaviour of the membranes is investigated. The water permeability is determined by measuring the flow rate of water through a $0.186 \mathrm{~cm}^{2}$ area of membrane with a constant pressure of 102,874 Pa across the membrane. The average values of water permeability from three trials are determined to be $\sim 1.52 \mathrm{~mL} / \mathrm{min}$ and $\sim 1.49 \mathrm{~mL} / \mathrm{min}$ for PAN membrane and silver coated PAN membrane respectively. This shows that the addition of silver particles did not alter the water permeability performance of the membranes. The normalized flow rates per unit area are determined to be $4902 \pm 402 \mathrm{LMH}$ and $4806 \pm 372 \mathrm{LMH}\left(\mathrm{LMH}=\mathrm{Liters} / \mathrm{M}^{2} / \mathrm{Hr}\right)$ for neat PAN membrane and silver coated PAN membrane respectively.

\subsection{Fitration Test Results}

Following this, the PAN membrane is tested for particulate filtration efficiency using aminemodified blue fluorescent latex beads of $2 \mu \mathrm{m}$ and $50 \mathrm{~nm}$ diameter. The results are displayed in Table 2 . As expected, the membrane fibres captured the highest percentage of $2 \mu \mathrm{m}$ latex beads. The capture efficiency is $81.2 \%$ for $2 \mu \mathrm{m}$ beads and $61.4 \%$ for $50 \mathrm{~nm}$ beads filtered through the same membrane. The SEM images of membrane fibres post-filtration are shown in Figure 7. It can be seen that the $2 \mu \mathrm{m}$ beads are significantly larger than the pore sizes, and are captured by the membrane's fibre mesh (Figure 7a,b). In contrast, there is little evidence of the $50 \mathrm{~nm}$ beads on the fibre surface (Figure 7c), except for a few densely packed clusters on the fibres (Figure 7d). 
Table 2. Particulate filtration efficacy of PAN membranes with latex beads.

\begin{tabular}{ccc}
\hline \multirow{2}{*}{ Sample } & \multicolumn{2}{c}{ Moles of Latex Beads $\left(\times \mathbf{1 0}^{\mathbf{5}}\right)$} \\
\cline { 2 - 3 } & Before Filtration & After Filtration \\
\hline PAN with $2 \mu \mathrm{m}$ & 222.24 & 41.76 \\
PAN with $50 \mathrm{~nm}$ & 164.64 & 66.24 \\
\hline
\end{tabular}

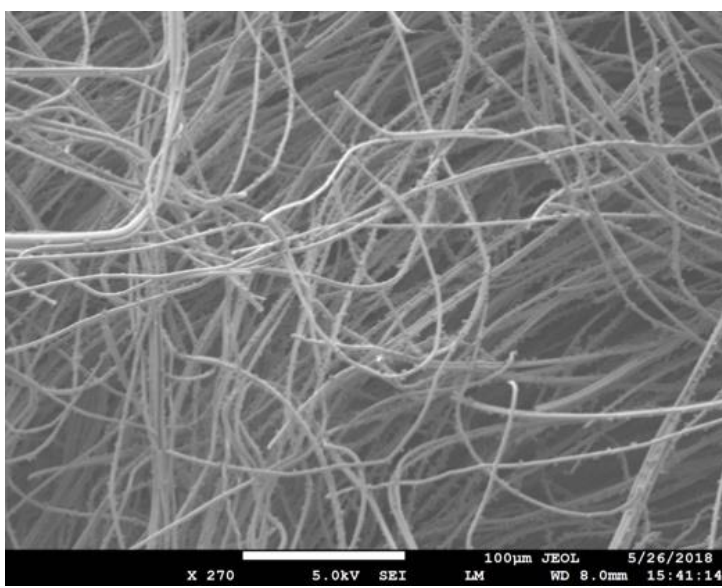

(a)

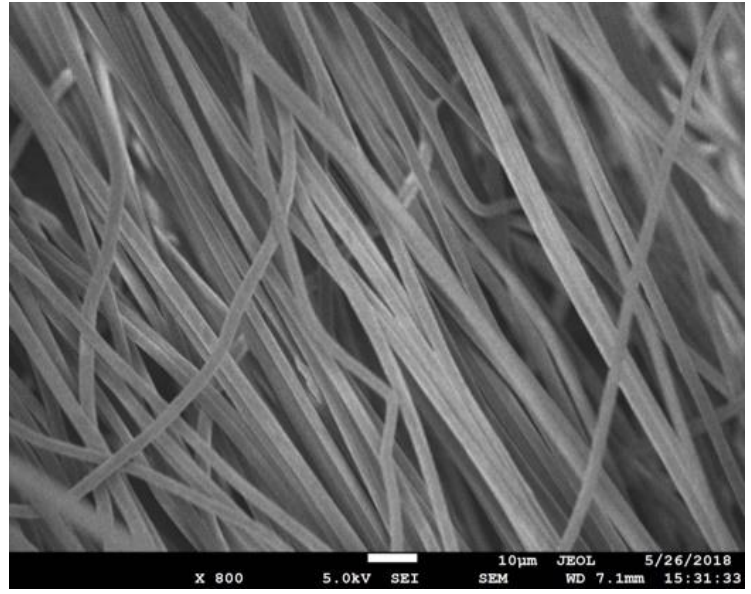

(c)

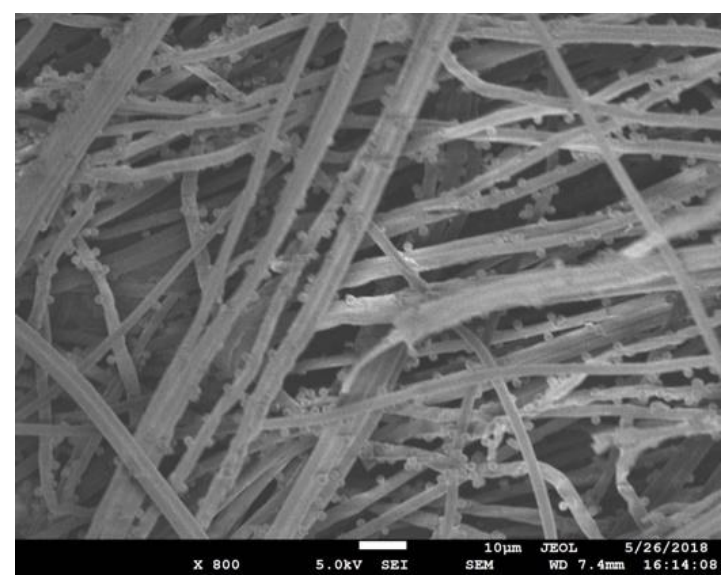

(b)

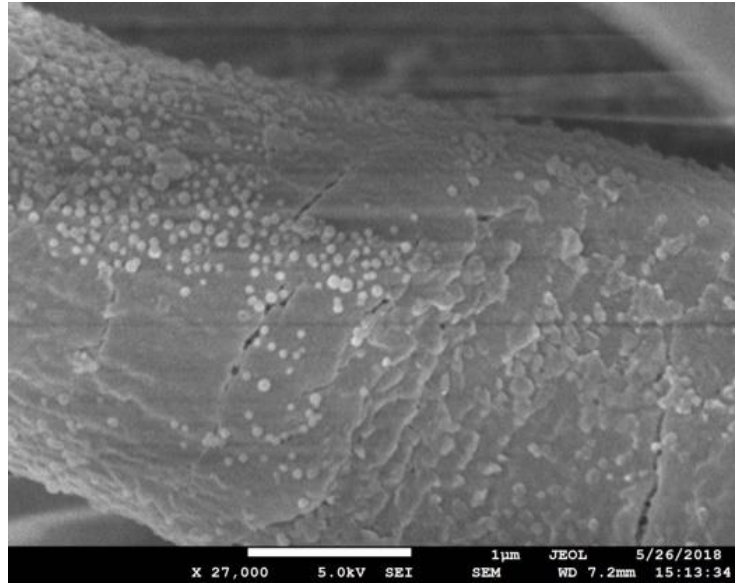

(d)

Figure 7. Filter membrane sample after filtration of solution with latex beads: (a) PAN with $2 \mu \mathrm{m}$ latex beads at $\times 270$ magnification; (b) PAN with $2 \mu \mathrm{m}$ latex beads at $\times 800$ magnification; (c) PAN with $50 \mathrm{~nm}$ latex beads at $\times 800$ magnification; (d) PAN with $50 \mathrm{~nm}$ latex beads at $\times 27,000$ magnification.

The membranes are reused to repeat the experiment three times to check for clogging. There was no significant drop in particulate filtration efficiency, suggesting that the filter membrane can be used multiple times.

\section{Conclusions}

Silver nanoparticle-functionalized PAN membranes were prepared by electrospinning followed by treating the membrane with hydroxylamine and $\mathrm{AgNO}_{3}$ by photoreduction. The resulting membrane had coordinated silver ions that were converted to silver nanoparticles. Immersion in hydroxylamine for $20 \mathrm{~min}$ and $\mathrm{AgNO}_{3}$ for $1 \mathrm{~h}$ resulted in an excellent anti-microbial membrane with total kill in $1 \mathrm{~h}$. With a longer immersion in either or both solutions, the membranes have a potential for better antimicrobial properties. Furthermore, the water permeability test showed that the 
membrane displayed adequate water filtration capabilities for water filtration membrane applications. The filtration test also showed that despite our large fibre diameters, the membrane managed to filter over $61.4 \%$ of $50 \mathrm{~nm}$ particles and over $81.2 \%$ of $2 \mu \mathrm{m}$ particles. This study thus proves the usability of PAN membranes with silver nanoparticles functionalization for water filtration purposes as an affordable and reliable solution for underdeveloped countries.

Author Contributions: Author A.B. conceptualized the experiments. L.K. conceptualized the antibacterial test and the interpretation of the results. S.A.P., R.N.D., and K.B. conducted the experiments. S.A.P. and R.N.D. wrote the manuscript. S.A.P. and R.N.D. contributed equally to this work.

Funding: This research was funded by SUTD-MIT International Design Center (IDC).

Acknowledgments: The authors would like to thank SUTD-MIT International Design Centre for kindly providing the funding for the research. The critical support by Tan Mei Chee, John Koh, Ding Meng and infrastructure provided by the Singapore University of Technology and Design (SUTD) during the manuscript preparation is highly appreciated.

Conflicts of Interest: The authors declare no conflict of interests.

\section{References}

1. Huang, L.; Arena, J.T.; Manickam, S.S.; Jiang, X.; Willis, B.G.; Mccutcheon, J.R. Improved mechanical properties and hydrophilicity of electrospun nanofiber membranes for filtration applications by dopamine modification. J. Membr. Sci. 2014, 460, 241-249. [CrossRef]

2. Siyanbola, T.O.; Gurunathan, T.; Akinsola, A.F.; Adekoya, J.A.; Akinsiku, A.A.; Aladesuyi, O.; Rajiv, S.; Mohanty, S.; Natarajan, T.S.; Nayak, S.K. Antibacterial and morphological studies of electrospun silver-impregnated polyacrylonitrile nanofibre. Orient. J. Chem. 2016, 32, 159-164. [CrossRef]

3. Sichani, G.; Morshed, M.; Amirnasr, M.; Abedi, D. In situ preparation, electrospinning, and characterization of polyacrylonitrile nanofibers containing silver nanoparticles. J. Appl. Polym. Sci. 2009, 116, 1021-1029. [CrossRef]

4. Mahapatra, A.; Garg, N.; Nayak, B.P.; Mishra, B.G.; Hota, G. Studies on the synthesis of electrospun PAN-Ag composite nanofibers for antibacterial application. J. Appl. Polym. Sci. 2011, 124, 1178-1185. [CrossRef]

5. Suja, P.S.; Reshmi, C.R.; Sagitha, P.; Sujith, A. Electrospun Nanofibrous Membranes for Water Purification. Polym. Rev. 2017, 57, 467-504. [CrossRef]

6. Shi, Y.; Li, Y.; Zhang, J.; Yu, Z.; Yang, D. Electrospun polyacrylonitrile nanofibers loaded with silver nanoparticles by silver mirror reaction. Mater. Sci. Eng. C 2015, 51, 346-355. [CrossRef] [PubMed]

7. Gao, Y.; Truong, Y.B.; Zhu, Y.; Kyratzis, I.L. Electrospun Antibacterial Nanofibers: Production, Activity, and In Vivo Applications. J. Appl. Polym. 2014, 131. [CrossRef]

8. Zhang, W.; Ronca, S.; Mele, E. Electrospun Nanofibres Containing Antimicrobial Plant Extracts. Nanomaterials 2017, 7, 42. [CrossRef] [PubMed]

9. Selvam, A.K.; Nallathambi, G. Polyacrylonitrile/silver nanoparticle electrospun nanocomposite matrix for bacterial filtration. Fibers Polym. 2015, 16, 1327-1335. [CrossRef]

10. Jiang, Z.; Zhang, H.; Zhu, M.; Lv, D.; Yao, J.; Xiong, R.; Huang, C. Electrospun soy-protein-based nanofibrous membranes for effective antimicrobial air filtration. J. Appl. Polym. Sci. 2018, 135, 45766. [CrossRef]

11. Pan, Y.J.; Chuang, W.S.; Lin, C.Y.; Chu, C.H. Composited Silver-Contained PA 6 Electrospun Fibers with Spunbond Nonwovens for Filtration Applications. Adv. Mater. Res. 2011, 287, 2626-2629. [CrossRef]

12. Rujitanaroj, P.-O.; Pimpha, N.; Supaphol, P. Preparation, characterization, and antibacterial properties of electrospun polyacrylonitrile fibrous membranes containing silver nanoparticles. J. Appl. Polym. Sci. 2010, 116, 1967-1976. [CrossRef]

13. Zhang, P.; Shao, C.; Zhang, Z.; Zhang, M.; Mu, J.; Guo, Z.; Liu, Y. In situ assembly of well-dispersed Ag nanoparticles (AgNPs) on electrospun carbon nanofibers (CNFs) for catalytic reduction of 4-nitrophenol. Nanoscale 2011, 3, 3357-3363. [CrossRef] [PubMed]

14. Lala, N.L.; Ramaseshan, R.; Bojun, L.; Sundarrajan, S.; Barhate, R.; Ying-Jun, L.; Ramakrishna, S. Fabrication of nanofibers with antimicrobial functionality used as filters: protection against bacterial contaminants. Biotechnol. Bioeng. 2007, 97, 1357-1365. [CrossRef] [PubMed] 
15. Kohsari, I.; Shariatinia, Z.; Pourmortazavi, S.M. Antibacterial electrospun chitosan-polyethylene oxide nanocomposite mats containing bioactive silver nanoparticles. Carbohydr. Polym. 2016, 140, 287-298. [CrossRef] [PubMed]

16. Zhang, L.; Luo, J.; Menkhaus, T.J.; Varadaraju, H.; Sun, Y.; Fong, H. Antimicrobial nano-fibrous membranes developed from electrospun polyacrylonitrile nanofibers. J. Membr. Sci. 2011, 369, 499-505. [CrossRef]

17. Heikkila, P.; Harlin, A. Electrospinning of polyacrylonitrile (PAN) solution: Effect of conductive additive and filler on the process. Express Polym. Lett. 2009, 3, 437-445. [CrossRef]

18. Faccini, M.; Borja, G.; Boerrigter, M.; Martín, D.M.; Crespiera, S.M.; Vázquez-Campos, S.; Aubouy, L.; Amantia, D. Electrospun Carbon Nanofiber Membranes for Filtration of Nanoparticles from Water. J. Nanomater. 2015, 2015, 1-9. [CrossRef]

19. Lee, J.; Yoon, J.; Kim, J.-H.; Lee, T.; Byun, H. Electrospun PAN-GO composite nanofibers as water purification membranes. J. Appl. Polym. Sci. 2018, 135, 45858. [CrossRef]

20. Zhang, L.; Gong, X.; Bao, Y.; Zhao, Y.; Xi, M.; Jiang, C.; Fong, H. Electrospun Nanofibrous Membranes Surface-Decorated with Silver Nanoparticles as Flexible and Active/Sensitive Substrates for Surface-Enhanced Raman Scattering. Langmuir 2012, 28, 14433-14440. [CrossRef] [PubMed]

21. Abdo, H.S.; Khalil, K.A.; Al-Deyab, S.S.; Altaleb, H.; Sherif, E.-S.M. Antibacterial effect of carbon nanofibers containing Ag nanoparticles. Fibers Polym. 2013, 14, 1985-1992. [CrossRef]

22. Wang, Y.; Yang, Q.; Shan, G.; Wang, C.; Du, J.; Wang, S.; Li, Y.; Chen, X.; Jing, X.; Wei, Y. Preparation of silver nanoparticles dispersed in polyacrylonitrile nanofiber film spun by electrospinning. Mater. Lett. 2005, 59, 3046-3049. [CrossRef]

23. Zhang, C.; Yang, Q.; Zhan, N.; Sun, L.; Wang, H.; Song, Y.; Li, Y. Silver nanoparticles grown on the surface of PAN nanofiber: Preparation, characterization and catalytic performance. Colloids Surf. A 2010, 362, 58-64. [CrossRef]

24. Wang, S.; Bai, J.; Li, C.; Zhang, J. Functionalization of electrospun $\beta$-cyclodextrin/polyacrylonitrile (PAN) with silver nanoparticles: Broad-spectrum antibacterial property. Appl. Surf. Sci. 2012, 261, 499-503. [CrossRef]

25. Chen, Y.; Liu, H.Y.; Zhang, Z.J. Characterization and Morphology of Composites Prepared from Polyacrylonitrile and Silver Nitrate. Appl. Mech. Mater. 2010, 26, 159-162. [CrossRef]

26. Shi, Q.; Vitchuli, N.; Nowak, J.; Caldwell, J.M.; Breidt, F.; Bourham, M.; Zhang, X.; Mccord, M. Durable antibacterial $\mathrm{Ag} /$ polyacrylonitrile $(\mathrm{Ag} / \mathrm{PAN})$ hybrid nanofibers prepared by atmospheric plasma treatment and electrospinning. Eur. Polym. J. 2011, 47, 1402-1409. [CrossRef]

27. Yu, D.G.; Zhou, J.; Chatterton, N.P.; Li, Y.; Huang, J.; Wang, X. Polyacrylonitrile nanofibers coated with silver nanoparticles using a modified coaxial electrospinning process. Int. J. Nanomed. 2012, 7, 5725-5732. [CrossRef] [PubMed]

28. Yang, Q.; Li, D.; Hong, Y.; Li, Z.; Wang, C.; Qiu, S.; Wei, Y. Preparation And Characterization Of A Pan Nanofibre Containing Ag Nanoparticles Via Electrospinning. Synth. Met. 2003, 137, 973-974. [CrossRef]

29. Guclu, S.; Pasaoglu, M.E.; Koyuncu, I. Membrane manufacturing via simultaneous electrospinning of PAN and PSU solutions. Desalin. Water Treat. 2015, 57, 8152-8160. [CrossRef]

30. Kumar, R.; Münstedt, H. Silver ion release from antimicrobial polyamide/silver composites. Biomaterials 2005, 26, 2081-2088. [CrossRef] [PubMed]

31. Zander, N.; Gillan, M.; Sweetser, D. Recycled PET Nanofibers for Water Filtration Applications. Materials 2016, 9, 247. [CrossRef] [PubMed]

(C) 2018 by the authors. Licensee MDPI, Basel, Switzerland. This article is an open access article distributed under the terms and conditions of the Creative Commons Attribution (CC BY) license (http:/ / creativecommons.org/licenses/by/4.0/). 